\title{
Ensino de Sistemas de Informação em Cursos de Computação: relato de experiência com uso de abordagem prática em TIC
}

\author{
Alternative Title: Teaching Information Systems for Computer Graduation \\ Courses: a report experience using a practical ICT approach
}

\author{
Edison Ishikawa \\ Departamento de Ciência da Computação \\ Instituto de Ciências Exatas \\ Universidade de Brasília \\ Campus Universitário Darcy Ribeiro \\ Caixa Postal 4466 - CEP 70.910-970 \\ Brasília - DF \\ ishikawa@unb.br
}

\author{
Célia Ghedini Ralha \\ Departamento de Ciência da Computação \\ Instituto de Ciências Exatas \\ Universidade de Brasília \\ Campus Universitário Darcy Ribeiro \\ Caixa Postal 4466 - CEP 70.910-970 \\ Brasília - DF \\ ghedini@cic.unb.br
}

\begin{abstract}
RESUMO
Ensinar a disciplina de Sistemas de Informação (SI) para alunos cujo curso seja na Computação, ligados a Tecnologia da Informação e Comunicações (TIC), exige uma adaptação na forma de abordar o assunto. Para atingir este objetivo, este artigo apresenta uma metodologia que exemplifica a aplicação dos conhecimentos de SI em uma organização de TIC ou em um setor de TIC. O conteúdo programático e sua importância foram avaliados aplicando-se um questionário aos alunos. As respostas revelaram que esta metodologia aumentou a compreensão dos alunos sobre SI e a vontade de aplicar este conhecimento nas suas atividades profissionais.
\end{abstract}

\section{Palavras-Chave}

Sistemas de Informação, Educação, Ementa

\begin{abstract}
Teaching Information Systems (IS) for computer students, with courses very related to Information and Communications Technology (ICT) requires adapting the subject with a different approach. To achieve this goal, this paper presents a methodology that exemplifies the application of IS knowledge inside ICT organizations or ICT departments. The content used and its importance were evaluated applying a questionnaire to the students. Responses showed that this method increased students' IS subject understanding and the desire to apply IS knowledge in their professional activities.
\end{abstract}

Permission to make digital or hard copies of all or part of this work for personal or classroom use is granted without fee provided that copies are not made or distributed for profit or commercial advantage and that copies bear this notice and the full citation on the first page. To copy otherwise, to republish, to post on servers or to redistribute to lists, requires prior specific permission and/or a fee.

SBSI 2015, May 26th-29th, 2015, Goiânia, Goiás, Brazil

Copyright SBC 2015.

\section{Categorias e Descritores do Assunto}

K.3.2 [Computer and Information Science Education]: Curriculum-Information systems education

\section{Termos Gerais}

Education

\section{Keywords}

Information Systems, Education, Model Curricula

\section{INTRODUÇÃO}

A abordagem usual de Sistemas de Informação (SI), encontrada nos principais livros da área [16, 28, 24], cujo público alvo são alunos e profissionais da área de administração e gestão de negócios, que precisam conhecer os conceitos de Tecnologia da Informação e Comunicações (TIC) de forma abrangente para gerir e tornar a sua organização competitiva, é por demais superficial para alunos de cursos de Computação. Além disso, a abordagem empregada nos cursos de graduação em SI, onde os conceitos relacionados a SI são vistos em maior profundidade em várias disciplinas [27], é por demais extensa para ser ministrada em uma única disciplina de SI. Devido a estes fatos, a disciplina SI destinada a estudantes dos cursos de Computação precisa ter uma abordagem distinta, para não se tornar repetitiva ou por demais superficial aos alunos que tem grande envolvimento com a área de TIC.

Para vivenciar o ambiente real no uso da TIC, os alunos são motivados a implementar os trabalhos em um ambiente de nuvem comercial $[21,1]$. Conceitos como escalabilidade, disponibilidade e flexibilidade de serviço, arquiteturas de aplicações Web, máquinas virtuais, balanceamento de carga, redes de computadores, servidores Web, Web services, banco de dados relacionais e distribuídos, proxies de cache, message services, monitoramento de serviços e níveis de acordo de serviço (SLA-Service Level Agreement), custo e segurança são utilizados normalmente no ambiente de implementação em nuvem [6]. 
Para alcançar os objetivos propostos, os SI desenvolvidos pertencem à atividade fim de TIC na organização, ou seja, o domínio de negócio ou conhecimento a ser modelado e implementado é da própria TIC. SI que usem a TIC apenas como um meio, ou sistemas de gestão de negócios, como o de administração escolar ou de comércio, os quais são comumente usados como exemplos em sala de aula, não foram usados uma vez que outras disciplinas do curso, tais como Engenharia de Software e Banco de Dados podem utilizálos. Por este enfoque, é possível perceber que a ênfase será preparar o profissional para atuar no setor de TIC de uma organização, ou também em uma organização cuja atividade fim seja a TIC ou dependa muito da TIC, como a Amazon, o Google, o Netflix, ou os prestadores de serviços de telecomunicações como GVT, VIVO, Sky, ou mesmo organizações públicas de TIC como o SERPRO, a DATAPREV, entre outras.

Esta proposta de metodologia de ensino de SI para cursos de Computação procura preencher a lacuna que existe em relação aos SI do domínio de negócio TIC, nos níveis operacional, de conhecimento, gerencial e estratégico de uma organização usando PBL. Ao final da disciplina, foi aplicado um questionário sobre os conteúdos específicos de SI e de TIC, sendo seus resultados avaliados.

O restante deste documento está dividido da seguinte forma: na Seção 2 é apresentada a proposta de metodologia de ensino. Na Seção 3 está ilustrada a proposta com alguns trabalhos realizados pelos alunos da disciplina SI nos cursos de computação. Na Seção 4 são apresentados os resultados da pesquisa sobre o conteúdo da disciplina SI realizada no final do período. Por fim, na Seção 5 são apresentadas as conclusões e trabalhos futuros.

\section{TRABALHOS RELACIONADOS}

Existem diversas propostas pedagógicas que procuram engajar o aluno no processo de aprendizagem, fazendo com que ele deixe de ser um mero receptor de informações para ser um agente pró-ativo na construção do seu próprio conhecimento. Estas abordagens que também são conhecidas como aprendizagem ativa melhoram a aprendizagem dos alunos. Neste sentido, [11] propõe um simulador para auxiliar no processo de ensino, enquanto [9] implementa campeonatos e desafios de programação.

Inclui-se como uma das técnicas de aprendizagem ativa a Aprendizagem Baseada em Problemas (Problem Based Learning-PBL). PBL propõe um processo de ensino e aprendizagem por meio do qual os estudantes conseguem um autoaprendizado dirigido através da solução de problemas. Com este enfoque em PBL, [8] usa técnicas de Design Thinking com PBL para co-projetar com seus alunos requisitos de um sistema de gerenciamento de aprendizagem. [18] usa PBL em disciplinas de Engenharia de Software e [10] usa um sistema de reconhecimento de expressões faciais para apoiar um ambiente virtual de aprendizagem baseado em agentes PBL.

Neste contexto, esta artigo apresenta uma proposta de ensino de SI com uma abordagem de aprendizagem ativa, onde o aluno se engaja na aquisição do conhecimento de maneira pró-ativa, dimininuindo a carga teórica e aumentando a prática. Desta forma, os alunos dos cursos de Computação implementam soluções, desenvolvendo SI dentro de uma organização real, ao mesmo tempo em que aprendem como TIC a permeia.

\section{PROPOSTA METODOLÓGICA}

O objetivo da metodologia é permitir que os alunos entendam como pessoas podem criar valor pelo uso da informação e como isto pode ser melhorado, com uma abordagem de ensino mais prática do que teórica. O aluno tem que pensar estrategicamente de forma a considerar como os tomadores de decisão podem usar a informação para criar valor, ou seja, criar um espaço para a inovação. Para isto, o aluno precisa aprender a pensar em como projetar, criar ou adaptar SI que criem este valor [13].

Para atingir este fim, o aluno de cursos de computação usa como estudo de caso problemas da área de gerenciamento de informações de TIC ou como inovações tecnológicas podem mudar radicalmente o domínio de negócio da empresa. Concomitantemente, também aprende como SI inovadores podem mudar o paradigma do modelo de negócios da empresa de forma que ela continue competitiva.

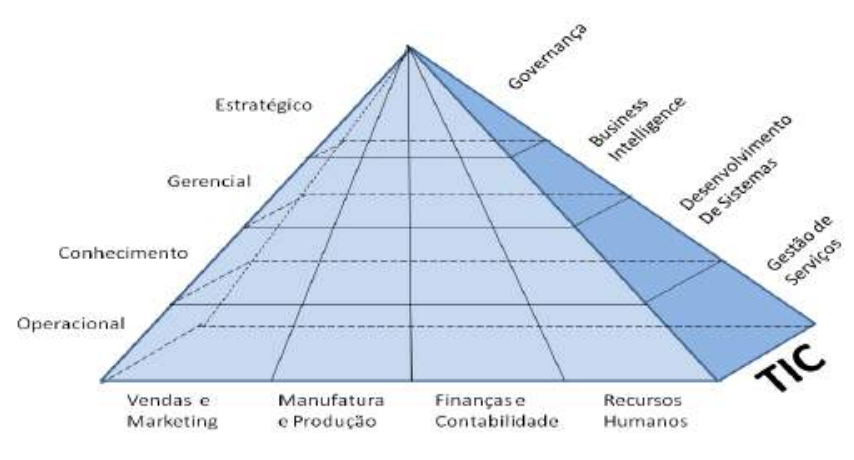

Figura 1: Estrutura organizacional.

A Figura 1 mostra a pirâmide da estrutura organizacional tradicional dividida em níveis de forma horizontal (níveis operacional, de conhecimento, gerencial e estratégico) e dividida verticalmente de forma funcional (vendas e marketing, manufatura e produção, finanças e contabilidade e recursos humanos). O interessante nesta pirâmide é o acréscimo de mais uma dimensão que permeia toda a organização, explicitando claramente o uso da TIC em todos os níveis e funções da empresa.

Salientamos que esta dimensão de TIC que permeia a organização, pode estar distribuída pelos diversos níveis decisórios da organização, ou mesmo centralizada em uma única unidade, por exemplo, superintendência, diretoria, ou departamento de TIC. Além disso, a área de TIC pode ser estruturada em níveis decisórios análogos aos existentes nos níveis hierárquicos da empresa. Outro ponto ressaltado na disciplina, é que esta unidade de TIC pode ter muita informação a ser gerenciada, que seus processos também permeiam a empresa e, portanto, seria interessante que os SI fossem integrados e, de preferência, unificados para diminuir custos.

Além disso, a disciplina SI dos cursos da área de computação tem o papel importante de relacionar as diversas outras disciplinas de Ciência de Computação dentro da subárea de Metodologias e Técnicas de Computação: Engenharia de Software, Banco de Dados, Linguagens de Programação e Processamento Gráfico [7]. Para isso, esta proposta procura fazer com que os alunos aprendam estes conhecimentos na 
prática, usando-os na implementação de um SI, algo semelhante a um hackthon [30].

\subsection{Justificativa}

Os alunos da disciplina SI dos cursos da área de computação já conhecem ou irão conhecer a TIC e necessitam complementar este conhecimento com a sua aplicação em organizações públicas ou privadas, agregando conhecimentos de Administração de Negócios, Teoria Geral de Sistemas, Gerenciamento de Projetos, entre outros.

A implementação de SI que resolvam, na prática, os problemas que os alunos irão enfrenter como profissionais da área de TIC é importante para motivar os alunos não só em relação à disciplina, mas ao seu curso de graduação, mostrando de forma direta a aplicação de SI na área de TIC e, como efeito colateral, diminuir a evasão existentes nos cursos de graduação [26].

Esta abordagem permite que o aluno também possa estudar, analisar, compreender e aperfeiçoar os processos organizacionais de TIC que permeiam a organização e aplicá-los na sua carreira profissional.

\subsection{Detalhes da proposta}

Como metodologia adotada, os alunos estudam o que os níveis organizacionais de um setor de TIC realizam e escolhem um nível organizacional de um departamento de TIC de uma instituição. Realizam um levantamento das necessidades de gestão da informação e inovação, elicitam os requisitos, modelam e analisam os processos e implementam um protótipo que soluciona o problema. Ou seja, procura-se aproveitar a motivação existente em competições de programação [9] como um hackthon, mas de forma mais sistematizada, com uso de metodologia de documentação e com a duração de um semestre letivo. No final do período os alunos apresentam seus trabalhos para toda a turma.

Entretanto, é preciso ressaltar, que o aluno de cursos de computação é orientado a procurar soluções com conhecimentos de como uma organização se estrutura, como ela funciona, que ela é um sistema formado de vários sistemas, sendo que muitos podem ser SI automatizados. Que em sistemas é preciso ter uma visão holística do todo e que o todo é maior do que a simples soma das partes (gestalt). Que uma organização é um sistema aberto e que precisa estar em homeostasia com o ambiente para sobreviver. Que sua solução pode afetar os sistemas existentes de formas imprevistas. Também são apresentadas noções de engenharia de sistemas com foco em aspectos importantes para permitir a inovação na especificação de sistemas.

Outro ponto ressaltado é o fato de que em empresas onde os SI não são integrados, o uso da TIC é estanque, ou seja, cada divisão funcional da organização, em seus níveis, pode ter sua própria solução de TIC e não existe um fluxo automatizado de informações entre as fronteiras departamentais. Já em empresas com SI integrados pode-se usar pacotes de integração comerciais (e.g., ERP - Enterprise Resource Planning, SCM - Supply Chain Management, CRM - Customer Relationship Management) ou implantar seus próprios aplicativos integrados, com vantagens e desvantagens em ambos os casos.

Para agregar o conhecimento de gestão com a TIC, o Business Process Management (BPM) foi utilizado [25], com foco no papel do analista de negócios na melhoria dos processos da organização, na necessidade de se integrar os diversos SI da organização, gestão de processos por indicadores e Balanced Score Card (BSC).

Para um aluno de um curso de computação, é fundamental que ele enxergue como é a organização em que ele irá trabalhar, como a TIC a permeia, como ela é organizada e, principalmente, como são os seus SI. Com esta finalidade, a classificação dos SI de TIC de acordo com os níveis hierárquicos da organização serão apresentados na sequência.

\subsubsection{Nível Operacional}

Neste ponto é apresentado ao aluno a unidade de TIC que realiza os serviços diários que mantém a infraestrutura de TIC de uma organização. O atendimento aos pedidos de manutenção dos computadores, da rede que não está conectada à Internet, do telefone VoIP (Voice over IP) que está mudo, da substituição do tonner da impressora que está no fim etc. É explicado que o ideal é que estes serviços estejam integrados com os demais sistemas dos outros departamentos da organização. Por exemplo, a necessidade da troca do cartucho de tonner da impressora pode gerar um pedido de compra para o Departamento de Compras. Também é mostrado que estes serviços de TIC precisam ser gerenciados de forma adequada, para que os usuários da TIC tenham um serviço de qualidade e para que a TIC contribua com a organização na sua missão. Ou seja, que neste nível os SI devem prover ao gerente de TIC a capacidade de acompanhar as atividades e transações elementares de serviços da organização. E que caso a Gestão dos Serviços de TIC seja grande e complexa ele pode recorrer a uma biblioteca com as melhores práticas, como a ITIL (Information Technology Infrastructure Libray) [20] ou o MOF (Microsoft Operations Framework) [19].

\subsubsection{Nivel de Conhecimento}

Neste nível organizacional ficam os responsáveis pelo desenvolvimento de soluções de software e hardware da empresa. Aqui a empresa integra novos conhecimentos nos negócios e auxilia a organização a controlar o fluxo de informações. Ou seja, é onde os programadores, analistas de sistemas, cientistas de computação etc trabalham. Eles não só agregam novos conhecimentos do negócio nos SI da empresa, mas também as viabilizam usando novas tecnologias no seu desenvolvimento. Por exemplo, para que os SI possam ser acessado pela Internet, medidas de segurança deverão ser implementadas utilizando o padrão OWASP [22]. Para que o SI seja escalável, ele pode ser implementado em nuvem [6]. Para mapear e otimizar os processos automatizados pelo SI os alunos utilizam as técnicas prescritas no BPM [14].

\subsubsection{Nivel Gerencial}

Neste nível os dados provenientes do nível operacional são consolidados em relatórios periódicos, os quais servem para os gerentes monitorarem, controlarem e tomarem decisões no setor de TIC. Que neste nível, sobre os dados produzidos pelos SI do nível operacional podem ser aplicadas técnicas de Business Intelligence (BI) para realizar inferências, para definir estratégias de competividade [4]. Que para as informações obtidas por relatórios e BI serem válidas, os dados advindos dos SI de nível operacional precisam ter qualidade, e que para isso é preciso governança sobre os dados.

\subsubsection{Nível Estratégico}

Neste nível são feitos os planejamentos de longo prazo da 
empresa. Ou seja, a alta direção da empresa necessita estabelecer uma Governança de TIC eficaz, para que ela garanta a criação de valor para os negócios da empresa, para que se crie uma cultura de TIC que preserve seus investimentos.

Para isso, os alunos precisam perceber que a TIC é um dos principais ativos de uma empresa, junto com os recursos humanos, físicos, financeiros, de propriedade intelectual e de relacionamentos e que o responsável pela área de TIC precisa sensibilizar e conscientizar a alta direção da empresa para a importância de se ter uma governança de TIC bem definida. Mais do que isso, ele tem que ser o parceiro da alta direção da empresa ou do negócio, que geralmente entendem pouco de TIC, apesar de precisarem da TIC, e que se se sentem frustrados com seus altos custos e limitados benefícios.

Os altos dirigentes veem que existe uma desconexão entre o negócio real e o que a TIC está fazendo. Ou seja, que eles (os atuais alunos dos cursos de computação e futuros profissionais de TIC) também precisam entender do negócio para poderem conversar par-a-par com a alta administração da empresa, para juntos poderem extrair benefícios estratégicos crescentes da TIC [29].

Dentro deste contexto, a metodologia proposta mostra ao aluno que a TIC, atualmente, é parte essencial para a competitividade do negócio, e que, a forma profissional de alinhar os objetivos de negócios e os objetivos de TIC é por meio de uma Governança de TIC profissional.

Os assuntos básicos de Governança de TIC que uma empresa precisa ter são introduzidos pela definição dos princípios de TIC, que são declarações claras, de alto nível, sobre como a TIC é utilizada no negócio. Para maior compreensão dos alunos, são mostradas regras de governança que, por exemplo, uma empresa tenha adotada e sua alta direção mostre firme vontade de que elas sejam cumpridas, como: "As soluções de TIC devem se basear em padrões de mercado, utilizando sempre que possível soluções abertas", ou "Todos na enpresa devem se preocupar com a corretude dos dados inseridos nos SI da empresa, de forma a assegurar a corretude dos relatórios gerenciais e a validade das informações obtidas por meio de softwares de Business Intelligence". Desta maneira, os alunos sem muita experiência em gestão de TIC entendem o que é governança e o que são as melhores práticas de governança de TIC preconizadas pelo COBIT [3].

\subsection{Contexto e Aplicação da Proposta}

Na Universidade de Brasília (UnB) a disciplina de SI é obrigatória para os cursos de Licenciatura em Computação (noturno) e Bacharelado em Ciência da Computação (diurno), sendo optativa para os cursos diurnos de Engenharia de Computação e Mecatrônica, além de poderem ser cursadas como módulo livre pelos alunos dos demais cursos de graduação. Os alunos dos diversos cursos de computação podem escolher o turno que preferem cursar SI, tendo a mesma carga horária de 60 horas por semestre, correspondendo a 4 créditos, com 4 horas/aula semanais, incluindo o semestre letivo que varia de 16 a 18 semanas.

Os alunos da licenciatura e do bacharelado podem cursar a disciplina a partir do quarto período, tendo como prérequisitos a disciplina de estrutura de dados ou programação sistemática. Semestralmente são oferecidas duas turmas com 30 a 40 alunos em ambos os turnos.

\subsubsection{Ementa e Programa Básico}

O objetivo da disciplina de SI é preparar o aluno para trabalhar com sistemas computacionais nas dimensões tecnológica, organizacional e humana. O foco de atenção da disciplina está na automação dos processos de negócio nas organizações, de maneira a racionalizar o uso de recursos e melhorar o processo de tomada de decisão, o controle de custos e a qualidade dos negócios realizados no âmbito organizacional. Para atingir estes objetivos, a disciplina é dividida em quatro módulos:

\subsubsection{Módulo I}

Fundamentos de SI. Conceitos básicos (dados, informação, conhecimento). Fundamentos de Teoria Geral de Sistemas. Abordagem sistêmica das organizações. Tipos de SI.

\subsubsection{Módulo II}

Processos de Negócio. Modelagem de processos de negócio. Implementação de processos de negócio. Gerência de processos de negócio.

\subsubsection{Módulo III}

Tecnologia da Informação. Recursos de tecnologia da informação e comunicações. Governança de tecnologia da informação.

\subsubsection{Módulo IV}

Aplicações. Noções de Análise e Projeto de Sistemas com UML e RUP. Noções de Projeto e Modelagem de Banco de Dados. Implementação de um sistema de informação.

\subsubsection{Instrumentos de Avaliação}

A avaliação consiste de 4 (quatro) trabalhos práticos. O primeiro trabalho é a definição do SI a ser desenvolvido, seu escopo e o levantamento de seus requisitos. O segundo trabalho consiste na modelagem do SI especificado no primeiro trabalho usando BPMN [12] e UML [23]. O terceiro trabalho é a implementação do SI definido no primeiro trabalho e modelado no segundo trabalho. O quarto trabalho é um artigo científico (com no mínimo 8 páginas preferencialmente em Inglês, utilizando o formato da Sociedade Brasileira de Computação (SBC)) sobre o trabalho desenvolvido com uma comparação dele com sistemas semelhantes, no que ele é diferente ou inovador em relação ao que já existe e a apresentação do artigo para a classe.

Além do trabalho, são aplicadas 02 (duas) provas individuais sem consulta, sendo que a primeira prova com o conteúdo dos módulos I e II e a segunda com o conteúdo dos módulos III e IV. Complementando a avaliação, os alunos realizam seminários apresentados e discutidos em classe, sobre assuntos atuais de TIC, como Computação Verde e suas implicações nas organizações, impressoras 3D e como ela poderá afetar os negócios.

\section{EXEMPLOS DE TRABALHOS}

Para exemplificar alguns dos resultados da aplicação desta metodologia, seguem três trabalhos realizados por alunos da disciplina SI no segundo semestre de 2014. Para a realização dos trabalhos os alunos seguiram o ciclo de vida para o desenvolvimento de sistemas preconizado pelo RUP [15], incluindo modelagem UML e do processo de negócios em BPMN.

\subsection{Sistema de Service Desk}




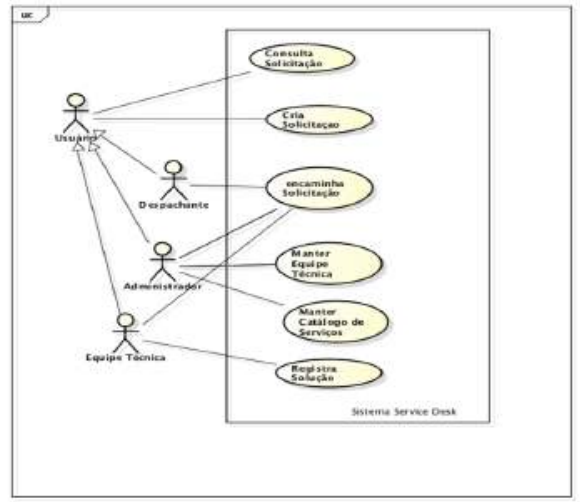

Figura 2: Diagrama de Casos de Uso do Sistema de Service Desk.

Este é um exemplo de SI de nível operacional, o qual foi desenvolvido pelos alunos da disciplina. Ele foi implementado em um ambiente de desenvolvimento em nuvem da Oracle, utilizando uma ferramenta de desenvolvimento expresso, o APEX [21]. O objetivo do sistema é ser um gerenciador de demandas de TI (Service Desk) no contexto de uma organização/empresa de pequeno/médio porte (entre 500 a 5000 funcionários), cujas solicitações relacionadas a TI são geradas pelas mais diversas áreas da instituição. A Figura 2 mostra um diagrama modelado pelos alunos utilizando a ferramenta Astah [2].

\subsection{SIGA : Sistema de Gerenciamento de Apli- cações}

Dada a importância, para qualquer organização que possua uma unidade específica de TIC, monitorar suas atividades no que diz respeito a desenvolvimento de sistemas, os alunos desenvolveram um Sistema de Gerenciamento de Aplicações denominado SIGA. O objetivo do sistema é monitorar, controlar e auditar as aplicações com base em regras de qualidade e seguranca definidas pela TI, bem como evitar o emprego desnecessário de esforço no desenvolvimento de soluções que podem já existir dentro da propria organização. Desta forma, os alunos pretendem ampliar a capacidade operacional e gerencial do departamento de TIC. O ganho operacional está em garantir maior homogeneidade e qualidade, enquanto relatórios gerenciais mostram o rumo do desenvolvimento de sistemas na organização, facilitando a tomada de decisão técnica. O sistema foi desenvolvido utilizando o serviço de computação em nuvem APEX [21], da Oracle. A Figura 3 mostra o diagrama de processos de negócios modelados pelos alunos segundo a notação BPMN utilizando o software bizagi [5]. Este pode ser considerado um SI para o nível de conhecimento da área de TIC de uma organização.

\subsection{Módulo de Controle de Suprimentos de Im- pressão}

Os alunos implementaram um SI de nível gerencial aproveitando um sistema de controle de estoque de toners e cartuchos de impressoras já existente na organização ABC. O módulo que eles desenvolveram acopla-se ao sistema existente, de maneira a utilizar os seus dados. Além de utilizar os dados do sistema, o módulo implementado pelos alunos

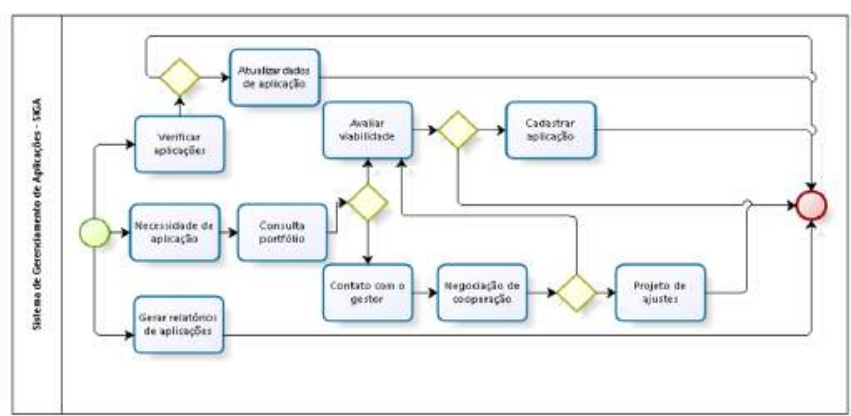

Figura 3: Mapeamento de processos de negócios do SIGA : Sistema de Gerenciamento de Aplicações.

agrega dados externos relativos ao mercado de impressoras e seus suprimentos de impressão, para auxiliar o setor de TIC na tomada de decisão no que diz respeito a aquisição, manutenção, provisionamento e descarte de impressoras no âmbito da referida organização. O sistema foi implementado em ambiente de homologação utilizando a tecnologia de computação em nuvem, por meio do serviço de hospedagem da Amazon (Amazon Web Services) [1].

Um dos gráficos deste módulo, Figura 4, facilita a leitura do consumo geral de cartuchos na empresa, permitindo aos gestores fazer uma análise comparativa do custo/benefício da aquisição de cada marca ou modelo de cartucho, orientando futuras aquisições de impressoras que apresentem suprimentos com melhor custo/benefício.

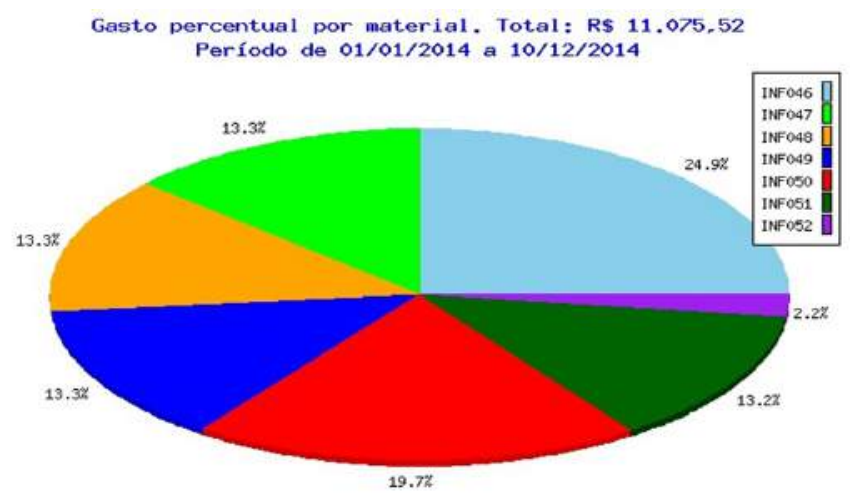

Figura 4: Gráfico gerado pelo Módulo Estratégico de Controle de Suprimentos de Impressão que facilita a leitura do consumo geral de cartuchos na empresa.

\section{QUESTIONÁRIO DE AVALIAÇÃO}

Para se avaliar a percepção dos alunos em relação ao conteúdo da disciplina SI foi aplicado, no final do semestre, um questionário de avaliação, cuja resposta era voluntária. A turma da disciplina SI era do turno noturno e contava com 23 alunos, dos quais 17 foram aprovados. Dos 23 alunos da turma, 15 responderam ao questionário. Dos alunos que não responderam o questionário, encontram-se 6 alunos que não 
obtiveram aprovação por terem faltado a mais de $25 \%$ das aulas.

Em levantamento informal realizado, verificou-se que alguns alunos deixaram de frequentar as aulas por motivos pessoais ou por alta carga de trabalho nas empresas em que trabalham. De qualquer forma, seria interessante apurar as causas com uma metodologia mais formal, de forma a descartar possíveis tendências não reveladas pela presente pesquisa. O questionário foi mandado para todos os alunos por meio do site de Ensino a Distância (Moodle) e por e-mail e está disponível em:http://goo.gl/forms/ou41ZiJhTQ.

A primeira parte do questionário levanta o perfil dos alunos, conforme apresentado na Figura 5, onde verifica-se que aproximadamente $70 \%$ dos alunos tem entre 18 e 24 anos.

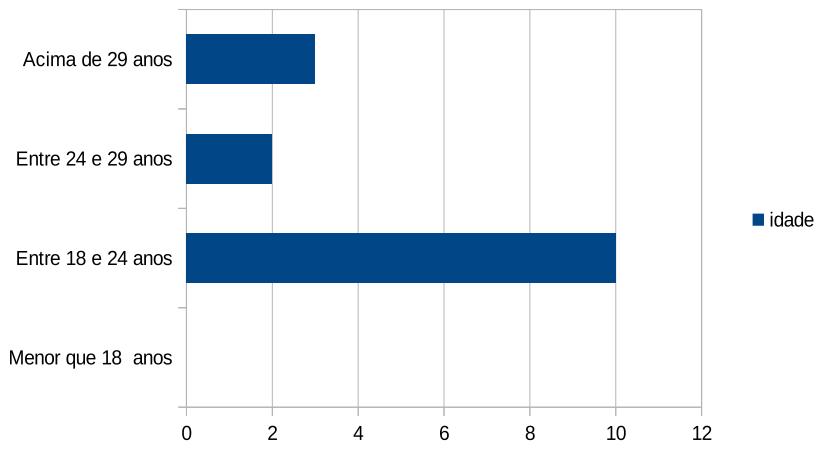

Figura 5: Divisão dos alunos por faixa etária.

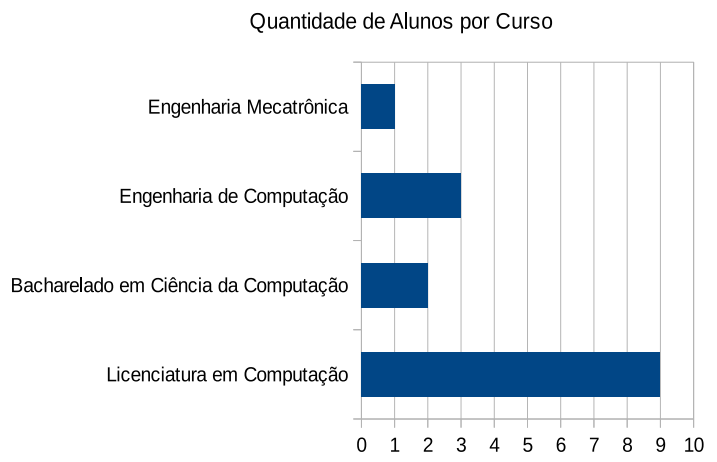

- alunos

Figura 6: Quantidade de alunos por curso na disciplina SI.

A Figura 6 mostra a classificaçãos dos alunos da turma por cursos. As Figuras 7, 8 e 9 mostram que $100 \%$ dos alunos da disciplina SI do turno noturno que exercem atividade remunerada o fazem no setor terciário da economia, sendo que destes, $85 \%$ trabalham no setor público. Nas instituições em que estes alunos trabalham, todos possuem SI automatizados e eles utilizam estes sistemas nas suas atividades laborais.

Após o leventamento do perfil, o questionário procurou levantar a opinião dos alunos em relação ao conteúdo da disciplina e a metodologia de ensino utilizada na disciplina.
Para esta análise utilizou-se a escala de Likert [17], cujas respostas poderiam variar de 1 a 5,1 para discordo totalmente e 5 para concordo totalmente, de forma que o aluno poderia marcar o número 3 , caso não soubesse responder. A Tabela 1 sumariza os resultados do questionário em relação

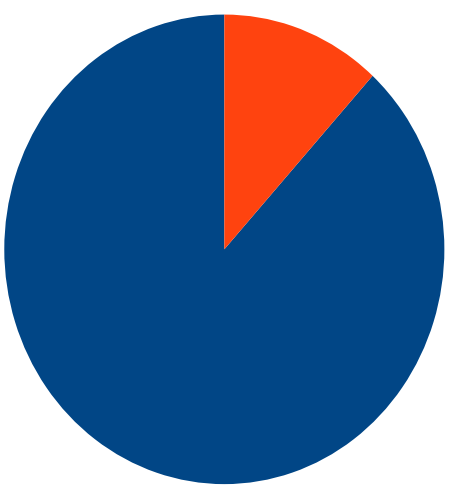

Exerce atividade remunerada Não exerce atividade remunerada

Figura 7: $87 \%$ dos alunos de SI exercem atividade remunerada.

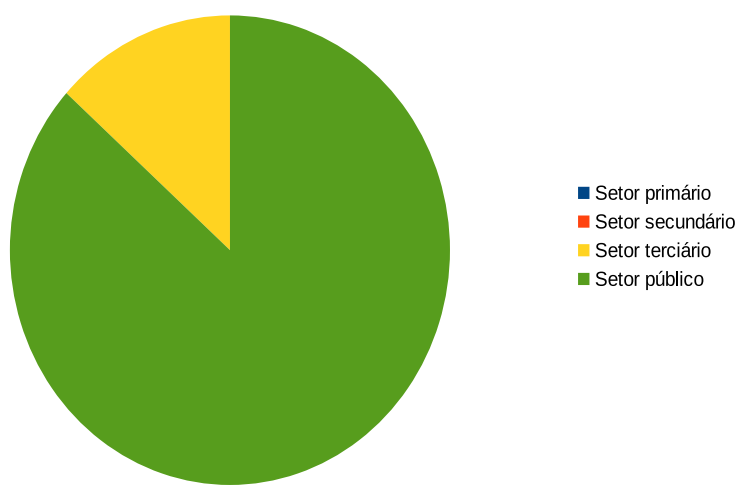

Figura 8: Dos alunos de SI que exercem atividade remunerada, todos são do setor de serviços, sendo que $85 \%$ trabalham no setor público.

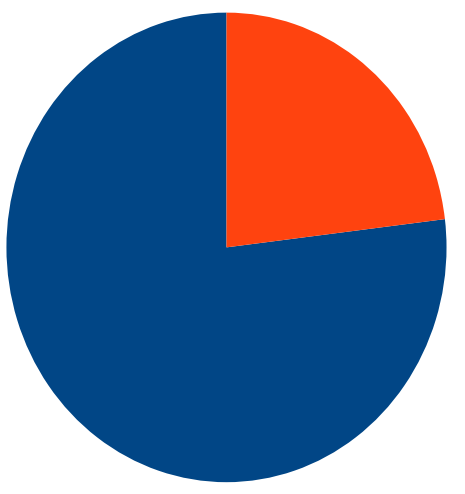

- Trabalha no setor de TIC - Trabalha em outro setor

Figura 9: Dos alunos de SI que exercem atividade remunerada, $77 \%$ trabalham no setor de TIC da sua organização 
ao conteúdo da disciplina de SI. As respostas 1 e 2, discordo totalmente e discordo, respectivamente, foram agrupadas no universo dos que discordaram da afirmação. As respostas 4 e 5 , concordo e concordo totalmente, respectivamente, foram agrupadas no universo dos que concordaram com a afirmação. A resposta 3 pode ser classificada como uma resposta indiferente ou de indecisão em relação a afirmação.

Na Pergunta 2.1 a maioria dos alunos concordou com a importância dos conhecimentos da disciplina SI na sua formação profissional, apenas um aluno não concordou nem discordou. Este aluno era do curso de Engenharia de Computação, cujo curso tem uma ênfase maior no conhecimento a nível de hardware e sofware básico, computação embarcada etc e que talvez, neste caso, se precise trabalhar melhor a necessidade do conhecimento de sistemas de mais alto nível para sua formação profissional, uma vez que o mesmo concordou que os conhecimentos transmitidos foram úteis (Pergunta 2.2), assim como todos os alunos que responderam o questionário.

Setenta e três por cento das respostas da Pergunta 2.3 concordam que SI é uma disciplina que motivou concluir o curso, o que mostra o acerto desta abordagem no ensino da disciplina SI para alunos de cursos de Computação.

De uma maneira geral, as respostas sobre o conteúdo programático da disciplina SI, conforme se verifica na Tabela 1 Perguntas 2.4 a 2.6, indicam que o conteúdo utilizado está no caminho certo. Ou seja, a disciplina SI deve abordar as futuras necessidades do profissional de TIC como gestor de negócios de uma organização genérica e como gestor de negócios de uma organização de TIC, capacitando os alunos a compreender os problemas de um departamento de TIC de uma organização e buscar soluções de SI que tragam vantagens competitivas a uma organização, empregando a TIC na sua solução.

As respostas às perguntas 2.7 e 2.8 mostram que o objetivo de valorizar a necessidade de se criar valor pelo uso da informação, criando espaço para a inovação, incentivando o aluno a pensar em como projetar, criar ou adaptar SI para este fim foi plenamente atingido.

A Pergunta 2.9 do questionário teve o objetivo de fazer uma sondagem a respeito de se abordar SI na área de ensino na disciplina SI, uma vez que a maioria dos alunos são de Licenciatura em Computação. Dos nove alunos de licenciatura que responderam ao questionário, três discordarm, um foi indiferente e cinco concordaram. Ou seja, percebe-se que os alunos da licenciatura estão divididos em relação a se abordar SI para ensino na disciplina. Ou seja, esta questão merece ser investigada mais a fundo.

Já em relação ao uso de SI que visem ao empreendedorismo, Pergunta 2.10, com a criação e o gerenciamento de novas empresas, apenas $40 \%$ das respostas foram positivas. Uma interpretação para este resultado é que estes alunos, mesmo já tendo uma colocação no serviço público, gostariam de ter a oportunidade de também se tornarem empreendedores do setor de TIC.

\section{CONCLUSÕES E TRABALHOS FUTUROS}

Os resultados da pesquisa de opinião feitos com os alunos da disciplina corroboram os objetivos propostos pela metodologia teórico/prática de ensino da disciplina SI. A disciplina SI deve dar uma ênfase maior nas futuras necessidades do profissional de TIC como gestor de negócios de uma organização genérica que possui um setor de TIC e ele precisará estar capacitado a gerenciar, entendendo o negócio da organização e ajudando a organização a cumprir seus objetivos.

A disciplina SI também deve preparar os alunos para serem gestores de negócios de uma organização de TIC, ou seja, organizações cuja atividade fim é a TIC. Por fim, a disciplina deve capacitar os alunos a compreender os problemas da área de TIC de uma organização e buscar soluções de SI que tragam vantagens competitivas a uma organização, desenvolvendo e implementando uma solução de TIC.

Como trabalhos futuros, pretende-se realizar uma pesquisa com os docentes da Disciplina SI de cursos de Computação do país, para colher opiniões sobre esta metodologia, a fim de aperfeiçoá-la. Pretende-se também realizar uma pesquisa com os alunos da disciplina SI, no início da disciplina, com o objetivo de levantar seu perfil, suas expectativas em relação à disciplina e possíveis dificuldades em concluir a disciplina, de forma a mapear a causa do não aproveitamento na disciplina por parte de alguns alunos. Para os alunos que tem SI como disciplina obrigatória e a frequentam pela segunda ou terceira vez, aplicar questionário para se levantar os motivos de não terem obtido aproveitamento na disciplina nas oportunidades anteriores. Desta maneira, espera-se eliminar possíveis dúvidas em relação ao bias da pesquisa realizada e conhecer melhor as causas do não aproveitamento na disciplina, de forma a tentar mitigá-las.

\section{REFERÊNCIAS}

[1] Amazon. Amazon Web Services. Disponível em http://aws.amazon.com/, consultado em fevereiro de 2015, 2015.

[2] Astah. Astah - UML Modeler. Disponível em http://astah.net/editions/community, consultado em fevereiro de 2015, 2015.

[3] I. I. S. Audit and C. Association. COBIT - Control Objectives for Information and Related Technology. Disponível em http://www.isaca.org/cobit, consultado em fevereiro de 2015, 2015.

[4] C. Barbieri. BI2 - Business Intelligence: Modelagem e Qualidade. Elsevier, 2011.

[5] Bizagi. Bizagi - BPMN Modeler. Disponível em http://www.bizagi.com/, consultado em fevereiro de $2015,2015$.

[6] R. Buyya and et al. Cloud computing and emerging IT platforms: Vision, hype, and reality for delivering computing as the 5th utility. Future Generation Computer Systems, 25(6):599-616, jun 2009.

[7] CNPQ. Tabelas de Áreas se Conhecimento. Disponível em http://www.cnpq.br/documents/ 10157/186158/TabelasAreasdoConhecimento.pdf, consultado em fevereiro de 2015, 2015.

[8] M. P. da Soledade Jr and et al. Experimenting with design thinking in requirements refinement for a learning management system. In Anais do IX Simpósio Brasileiro de Sistemas de Informação, pages 182-193, João Pessoa, PB, 2013.

[9] L. A. Digiampietri and et al. Complementando o aprendizado em programação: Experiências no curso de sistemas de informação da USP. In Anais do VIII Simpósio Brasileiro de Sistemas de Informação, pages 779-790, São Paulo, SP, 2012.

[10] F. A. Diniz and et al. Um sistema de reconhecimento 
Tabela 1: Resultados das perguntas referentes ao conteúdo da disciplina SI

\begin{tabular}{|l|c|c|c|}
\hline Perguntas & \% Concordo & \% Indeciso & \% Discordo \\
\hline 2.1 A disciplina SI é importante para a minha formação profissional. & 93,3 & 6,7 & 0 \\
\hline 2.2 A disciplina SI agregou conhecimentos úteis. & 100 & 0 & 0 \\
\hline $\begin{array}{l}2.3 \text { A disciplina SI me motivou a concluir o curso de graduação que estou } \\
\text { fazendo. }\end{array}$ & 73,3 & 26,7 & 0 \\
\hline $\begin{array}{l}\text { 2.4 A disciplina SI precisa abordar, em termos de conteúdo ministrado, as } \\
\text { minhas futuras necessidades como gestor de negócios de uma organização. }\end{array}$ & 86,6 & 6,7 & 6,7 \\
\hline $\begin{array}{l}\text { 2.5 A disciplina SI precisa abordar, em termos de conteúdo ministrado, as mi- } \\
\text { nhas futuras necessidades como profissional da área de TIC, seja como executor } \\
\text { ou gestor de TIC de uma organizaçãoo. }\end{array}$ & 86,6 & 13,4 \\
\hline $\begin{array}{l}\text { 2.6 A disciplina SI precisa abordar, em termos de conteúdo ministrado, as } \\
\text { minhas futuras necessidades como profissional da área de TIC, como gestor de } \\
\text { negócios de uma organização cuja atividade fim é TIC. }\end{array}$ & 80 & 20 & 0 \\
\hline $\begin{array}{l}2.7 \text { A disciplina SI deve capacitar o aluno para achar soluções de SI que tragam } \\
\text { vantagem competitiva à uma organização. }\end{array}$ & 93,3 & 6,7 & 0 \\
\hline $\begin{array}{l}\text { 2.8 A disciplina SI deve capacitar o aluno a compreender os problemas das } \\
\text { organizações e como TIC pode ajudar a solucioná-las. }\end{array}$ & 100 & 0 \\
\hline $\begin{array}{l}\text { 2.9 A disciplina SI também deve abordar Sistemas de Informação para a ativi- } \\
\text { dade fim de ensino, uma vez que alunos de licenciatura em computação podem } \\
\text { frequentá-la. }\end{array}$ & 46,7 & 20 & 0 \\
\hline $\begin{array}{l}\text { 2.10 A disciplina SI deve se concentrar mais no aspecto organizacional, focando } \\
\text { na criação e gerenciamento de empresas. }\end{array}$ & 40 & 26,7 & 33,3 \\
\hline
\end{tabular}

de expressões faciais para apoiar um ambiente virtual de aprendizagem. In Anais do IX Simpósio Brasileiro de Sistemas de Informação, pages 463-474, João Pessoa, PB, 2013.

[11] P. R. E. Gestal and R. M. de Barros. Proposta de um simulador para auxiliar no processo de ensino do Scrum. In Anais do X Simpósio Brasileiro de Sistemas de Informação, pages 723-736, Londrina, PR, 2014.

[12] O. O. M. Group. Business Process Model and Notation. Disponível em http://www.bpmn.org/, consultado em fevereiro de 2015, 2015.

[13] J. F. N. Jr, M. Chen, and T. D. M. Purdin. Systems development in information research. Journal of Management Information Systems, 7(3):89-106, Winter 1990-91.

[14] O. P. Júnior and R. Scuglia. Mapeamento e Gestão por Processos - BPM. M. Books do Brasil Editora Ltda, 2011.

[15] P. Kroll, P. Kruchten, and G. Booch. The Rational Unified Process Made Easy: A Practitioner's Guide to the RUP: A Practitioner's Guide to the RUP. Addison-Wesley Professional; 1 edition, 2003.

[16] K. Laudon and J. Laudon. Management Information Systems: Managing the Digital Firm. Prentice Hall, New Jersey, 2015.

[17] R. Likert. A technique for the measurement of attitudes. Archives of Psychology, 22(140):55, 1932.

[18] S. Mergen and et al. Using pdca as a general framework for teaching and evaluating the learning of software engineering disciplines. In Anais do IX Simpósio Brasileiro de Sistemas de Informação, pages 451-462, João Pessoa, PB, 2013.

[19] Microsoft. Microsoft Operations Framework v4.0. Disponível em http://www.microsoft.com, consultado em fevereiro de 2015, 2008.

[20] OGC. Introduction to the ITIL Service Life Cicle.
TSO, 2011.

[21] Oracle. Oracle Application Express. Disponível em https://apex.oracle.com/i/index.html, consultado em fevereiro de 2015, 2015.

[22] OWASP. The Open Web Application Security Project. Disponível em https://www.owasp.org/, consultado em fevereiro de 2015, 2008.

[23] H. Podeswa. UML For The IT Business Analyst. Cengage Learning PTR; 2 edition, 2009.

[24] R. Rainer and E. Turban. Introduction to Information Systems: Support and Transforming Business. Wiley, 2008.

[25] C. G. Ralha and J. H. C. Fernandes. Ensino de sistemas de informação para cursos de graduação em computação: Uma experiência integradora e inovadora. In Anais do XIV Workshop sobre Educação em Computação, pages 88-97, Campo Grande, MS, 2006.

[26] O. H. M. L. Roberto Leal Lobo e Silva Filho, P. R. Motejunas. A evasão no ensino superior brasileiro. Cadernos de Pesquisa, 37(132):641-659, set/dez 2007.

[27] SBC. Currículo de referência da sociedade brasileira de computação para cursos de graduação em computação e informática. In http://www.sb.org.br. SBC, 1999.

[28] R. M. Stair and G. W. Reynolds. Principles of Information Systems: a managerial approach. Thomson Learning, 2006.

[29] P. Weill and J. W. Ross. IT Governance - How Top Performers Manage IT Decision Rights for Superior Results. Harvard Business School, 2004.

[30] Wikipedia. Hackathon. Disponível em http://en.wikipedia.org/wiki/Hackathon, consultado em fevereiro de 2015, 2015. 